\title{
La lesión a los derechos de la personalidad en la jurisprudencia de la instancia de recurso especial brasileña
}

\author{
Recibido: 17 de marzo de $2020 \bullet$ Aprobado: 13 de mayo de 2020 \\ https://doi.org/10.22395/ojum.v20n4la6
}

Gilberto Fachetti Silvestre

Universidad Federal de Espírito Santo (UFES), Vitória, Brasil gilberto.silvestre@ufes.br https://orcid.org/0000-0003-3604-7348

Bruna Figueira Marchiori Universidad Federal de Espírito Santo (UFES), Vitória, Brasil brunafigueiramarchiori@gmail.com https://orcid.org/0000-0003-1869-0567

\section{RESUMEN}

Esta investigación encontró divergencias en el establecimiento de la compensación pecuniaria (el quantum) de daño moral. En este sentido, el objetivo fue identificar si actualmente el Tribunal Superior de Justicia de Brasil exige probar el dolor o el sufrimiento para la ocurrencia de daño moral y para justificar la indemnización. Para esto, se realizaron estadísticas de juzgados con el objetivo de verificar si existe jurisprudencia sobre el tema. En este sentido, la investigación se desarrolló con enfoque cualicuantitativo (cualitativo y cuantitativo). Se realizó una revisión de la literatura para profundizar los conceptos teóricos y teorías respecto a este tema. La investigación adoptó la metodología de revisión sistemática de jurisprudencia y el método fue el inductivo. Se buscó establecer una referencia general basada en el conocimiento de cierto número de datos singulares para la elaboración de una conclusión genérica. Como resultado, la investigación ofrece la comprensión mayoritaria actual del Tribunal Superior de Justicia (ST) por sus siglas en portugués) sobre la no exigencia del elemento psíquico en las acciones de indemnización por daños morales.

Palabras clave: Tribunal Superior de Justicia; derechos de la personalidad; pretium doloris; daño in re ipsa; daño moral. 


\section{Injury to Personality Rights in the Jurisprudence of the Brazilian Special Instance}

\section{ABSTRACT}

This is a research that found the existence of divergences in the establishment of the pecuniary compensation (the quantum) of moral damage and the objective was to identify if the Superior Court of Justice currently requires proof of pain or suffering for the occurrence of moral damage and to justify compensation. For this, court statistics were carried out to verify if there is jurisprudence on the subject. In this sense, the research was developed with a qualitative-quantitative approach (qualitative and quantitative). A review of the literature was carried out to deepen the theoretical concepts and theories regarding this topic. The research adopted the methodology of systematic review of jurisprudence and the method was inductive, seeking to establish a general reference based on the knowledge of a certain number of unique data for the elaboration of a generic conclusion. As a result, the investigation offers the current majority understanding of the STJ on the non-requirement of the psychic element in actions for compensation for moral damages.

Keywords: Superior Court of Justice; rights of personality; pretium doloris; damage in re ipsa; moral damages.

\section{A lesão aos direitos da personalidade na jurisprudência da instância de recurso especial brasileira}

\section{RESUMO}

Trata-se de pesquisa que constatou a existência de divergências na fixação da compensação pecuniária (o quantum) do dano moral e cujo objetivo foi identificar se o Superior Tribunal de Justiça atualmente exige prova de dor ou sofrimento para a ocorrência de dano moral e justificar compensação. Para isso, foram realizadas estatísticas judiciais para verificar se há jurisprudência sobre o assunto. Nesse sentido, a pesquisa foi desenvolvida com abordagem qualitativa-quantitativa (qualitativa e quantitativa). Uma revisão da literatura foi realizada para aprofundar os conceitos e teorias teóricas sobre este tópico. A pesquisa adotou a metodologia de revisão sistemática da jurisprudência e o método foi o indutivo, buscando estabelecer uma referência geral baseada no conhecimento de um determinado número de dados únicos para a elaboração de uma conclusão genérica. Como resultado, a investigação oferece o entendimento majoritário atual do STJ sobre a não exigência do elemento psíquico nas ações de indenização por danos morais.

Palavras-chave: Superior Tribunal de Justiça; direitos da personalidade; pretium doloris; dano in re ipsa; dano moral. 


\section{INTRODUCCIÓN}

Este trabajo es el resultado final de una investigación realizada entre 2018 y 2019 bajo el Programa de Iniciación Científica Institucional (PIIC) de la Universidad Federal de Espírito Santo (UFES), Vitória-ES, Brasil, y financiado con recursos del Consejo Nacional de Investigación (CNPq) de Brasil.

Fue una de las primeras investigaciones llevadas a cabo dentro del grupo de investigación Desafíos del proceso: impactos del Código de Proceso Civil en el sistema jurídico civil, dirigido a la investigación sobre la protección judicial diferenciada de los institutos de derecho civil brasileños basada en el Código de Proceso Civil (2015).

Desde una perspectiva práctica, esta investigación examinó cómo el daño moral — en un sentido amplio — se caracteriza y aplica dentro del Tribunal Superior de Justicia brasileño (ST) y se basa en elementos y conceptos de la civilística y la procesalística contemporáneas.

El Tribunal Superior de Justicia es la instancia brasileña especial de recurso, cuya función principal es estandarizar la jurisprudencia federal en Brasil.

La elección del tema está estrechamente asociada con su relevancia. Según datos del Consejo Nacional de Justicia (CNJ, 2017), en el Relatório justiça em números se están procesando un total de 1.001 .889 demandas relacionadas con responsabilidad civil/ indemnización por daños morales en los poderes judiciales de Brasil. Aunque el tema está bastante presente en la literatura jurídica y la actividad judicial brasileñas, los requisitos necesarios para la concesión de la indemnización fueron controvertidos en la hipótesis preliminar de esta investigación. Y esto sucedió tanto en el ámbito judicial (piso y apelación e instancias especiales), como en la literatura jurídica.

Fue encontrada una división: hay decisiones de los tribunales y trabajos científicos que respaldan la necesidad de verificar un elemento psíquico, a saber, la identificación de la presencia de dolor o sufrimiento por parte de la víctima, de modo que realmente ocurra un daño moral. Por otro lado, hay entendimientos que sostienen que, para configurar el daño moral, una violación pura y simple de cierto derecho de personalidad es suficiente, y en este caso es totalmente innecesario buscar la presencia de los elementos de dolor o sufrimiento para su caracterización.

Esta divergencia está presente en las decisiones del STJ, tal como se encuentra en la investigación de juzgados entre los años 2012 y 2018. Una hipótesis preliminar es que tal situación podría generar incertidumbre legal y procesal en el Tribunal Superior.

Por lo tanto, era imperativo analizar las bases teóricas de las decisiones más recientes del STJ para comprender cómo el tribunal ha entendido la necesidad de verificar el elemento volitivo en las acciones de indemnización por daños morales. La elección del Tribunal Superior de Justicia se justifica por su función de estandarización 
de jurisprudencia y por pronunciar decisiones juzgadas como paradigmas, especialmente en el contexto de la valoración de los precedentes por el Código de Procedimiento Civil de 2015.

En una monografía sobre el tema, Felipe Nobre de Morais (2013) encuestó y analizó treinta y siete decisiones de las cuatro salas de la Corte Superior, de enero de 2012 a agosto de 2013. En su análisis, identificó que el $67,56 \%$ de las decisiones analizadas asocian daño moral a la identificación del elemento psíquico.

Dada la naturaleza dinámica del derecho, especialmente en la cotidiano del STJ, surgió la necesidad de actualizar estos datos. Se tomaron como referencia los juzgados de enero de 2014 a enero de 2017. De esta manera, se trató de identificar si el tribunal mantuvo el entendimiento al que estaba afiliado en 2012 y 2013. Asimismo, se discutieron y analizaron los reflejos de su posición, tanto pasada como actual.

El objetivo general de esta investigación fue identificar si actualmente existe un requisito por parte del Tribunal Superior de Justicia para probar el dolor o el sufrimiento para la caracterización y ocurrencia de daño moral y, a partir de esto, justificar la indemnización lenitiva correspondiente. Para implementar este objetivo, se realizaron estadísticas de recursos juzgados para verificar si existe jurisprudencia sobre el tema. Obviamente, la investigación profundizó, como premisa, las nociones de daño moral identificadas en la literatura jurídica, y buscó encontrar la posición doctrinal mayoritaria en torno al tema.

Esto trabajo no tuvo como objetivo profundizar conceptos teóricos, sino solo informarlos —o presentarlos - como premisas para comprender el verdadero enfoque de la investigación: las estadísticas de la jurisprudencia. En otras palabras, el artículo no es para dar profundidad a las teorías, sino comprender su aplicación en la corte superior.

En este sentido, la investigación se desarrolló como un enfoque cualicuantitativo (cualitativo y cuantitativo). Se realizó una revisión de la literatura para profundizar los conceptos teóricos y teorías de la civilistica y la procesalística explorados con respecto a este tema específico. Además, la investigación adoptó la metodología de revisión sistemática de jurisprudencia, específicamente utilizando el análisis de los juicios del STJ.

El método utilizado fue el inductivo. Se buscó establecer una referencia general basada en el conocimiento de cierto número de datos singulares, es decir, a partir de datos singulares para la elaboración de una conclusión genérica.

La investigación, por lo tanto, tiene la intención de ofrecer a los operadores del derecho la comprensión actual del Tribunal Superior de Justicia sobre la exigencia o no del elemento psíquico en las acciones de indemnización por daños morales. Con 
esto, tiene la intención de ofrecer aspectos prácticos a la comunidad jurídica para la operatividad del asunto en los tribunales.

\section{La CARACTERIZACIÓN DEL DAÑO MORAL EN BRASIL EN LOS ÚLIIMOS TREINTA AÑOS: ¿PRETIUM DOLORIS O PREJUICIO IN RE IPSA?}

El daño moral —en sentido amplio, es decir, como sinónimo de daño no patrimonial o personal - es un concepto estrechamente relacionado con la personalidad civil. Este concepto, desde el personalismo ético, es el atributo que hace de la persona un sujeto de derecho y un valor en sí mismo.

La personalidad garantiza la protección de la persona en sus aspectos fundamentales, a saber, psicosomático, espiritual e intelectual. Cada uno de estos aspectos está protegido por situaciones jurídicas basadas en los llamados derechos de la personalidad.

Cuando se produce una lesión a un derecho de la personalidad, hay una reducción en el valor de la personalidad que consiste en un prejuicio no patrimonial o patrimonial. Aquí es donde se habla de daño moral, que es el resultado del incumplimiento del deber de incolumidad respecto a la persona humana (Noronha, 2013, pp. 579-590).

El historial de responsabilidad civil por daños morales en el Civil law muestra que su aceptación en la doctrina y la jurisprudencia es reciente. En Italia, Giampietro Chironi (1925) no entendía cómo sería posible compensar el dolor a través de la pecunia y, especialmente, cómo se estimaría. No estuvo de acuerdo con que el daño podría ser estimado por el juez, ya que se haría con los criterios personales del magistrado. Sería imposible valorar el daño moral:

¿Cómo es posible compensar el dolor con dinero? Si es cierto y sincero, ¿cómo puedo estimarlo? Se contesta que es estimada por el juez, pero luego la estimación se abandona al criterio personal del magistrado, y esto no se concilia con la naturaleza de la indemnización: se dice que es imposible evaluar el daño moral en dinero, pero que si el magistrado no puede otorgando una compensación exacta, esto no significa que no pase la exactitud de la compensación, sino la imposibilidad de evaluar. (Chironi, 1925, p. 100, traducción propia)

En Francia, Henri Mazeaud y Léon Mazeaud (1934) señalaron que los tribunales franceses solo consideraron un esquema pecuniario cuando el daño moral tuvo repercusiones en el patrimonio de la víctima.

En Brasil, Salomão Resedá (2017) ha dicho que

durante décadas, el derecho brasileño vivió bajo la égida de una responsabilidad civil patrimonial donde solo se podría hablar de indemnización y, en consecuencia, de daño cuando se identificara algún tipo de siniestro. La reducción del patrimonio fue necesaria y fundamental para diseñar el daño material. (p. 10, traducción propia) 
Aunque en la civilistica y en la procesalística contemporáneas ya no se discute si hay una indemnización por daños a los valores inmateriales de la persona, hay un problema que aún no se ha resuelto de manera efectiva y que debe ser resuelto a riesgo de violar la seguridad jurídica e la imparcialidad de las decisiones: se trata de lo que se entiende por daño moral. Hay muchas definiciones de daño moral en la literatura jurídica, variables entre ellas.

Silvio de Salvo Venosa (2004, p. 39) se refiere a un elemento psíquico. En este sentido, el daño moral es el que afecta el estado de ánimo psicológico, moral, intelectual y físico de una víctima en particular.

Para Caio Mário da Silva Pereira (2002), el daño moral es "cualquier sufrimiento humano que no sea causado por una pérdida pecuniaria" (p. 54, traducción propia). Eso representaría un ataque a la reputación de la víctima, su autoridad legítima, su modestia, su seguridad y tranquilidad, su amor estético ("amor propio"), la integridad de su inteligencia y sus afectos.

Sin embargo, debe afirmarse que el dolor, el asombro, la humillación, la vergüenza, las lesiones, etc. son el contenido del daño moral, no su concepto, porque tal daño es en realidad la infracción a los derechos de la personalidad.

En este sentido, se enfrenta un problema técnico: los daños morales no se pueden indemnizar porque el dolor, el sufrimiento y la honradez no se pueden estimar en dinero. Con la indemnización pecuniaria de lesiones personales no se pretende una indemnización, sino una compensación que, ciertamente, no restablecerá la situación legal anterior, pero permitirá a la víctima aliviar la incomodidad causada por el daño y hacer que el agente tome conciencia del daño que has causado.

A partir de ahí, hay una perspectiva contemporánea diferente a la de hace muchos años. Sergio Cavalieri Filho (2003) afirma que el "dano moral, à luz da Constituição vigente, nada mais é do que violação do direito à dignidade" (p. 87). Del mismo modo, para Maria Celina Bodin de Moraes (2003), el daño moral es lo que afecta y ofende la dignidad de la persona humana:

[A]firmar que el daño moral es "dolor, vergüenza, humillación o vergüenza" es similar a darle el epíteto de "mal evidente". A través de estas palabras, no está legalmente conceptualizado, solo se describen sensaciones y emociones desagradables, que pueden ser justificadas, comprensibles, razonables, incluso moralmente legítimas, pero que, si no se deben a "daños injustos", o mejor, daños a situaciones merecedores de protección por orden, no son reparables. [...]. Si la violación de la situación legal subjetiva fuera del balance general implica un mal presentimiento no es algo que el Derecho pueda o deba investigar. Lo que el sistema legal puede (y debe) hacer es concretar o densificar la cláusula de protección humana, sin 
admitir que las violaciones de la igualdad, la integridad psicofísica, la libertad y

la solidaridad (social y familiar) siguen sin resolverse. (p. 129, traducción propia) ${ }^{1}$

Se ve, por lo tanto, que el daño moral es causado por la violación de un derecho subjetivo no patrimonial protegido por el ordenamiento jurídico — en el caso brasileño por la cláusula general de protección de la personalidad (Código Civil, 2002, arts. 1121; Constitución de la República Federativa de Brasil, 1988, art. 1, III)—. Por lo tanto, para hablar de daño moral, es necesario probar qué derecho de personalidad ha sido dañado (Silvestre, Hibner y Ramalho, 2018, pp. 9-20).

A partir de la Constitución de la República (1988), la compensación por daños morales fue provista por ley expresamente para todos las materias civiles (artículo 5, V y X). En el período hasta el Código Civil (2002), el daño moral fue en gran medida caracterizado como sufrimiento resultante de una lesión a la persona. La caracterización del daño moral estaba estrechamente vinculada al elemento anímico dolor. Por lo tanto, la compensación pecuniaria por daños morales se consideraba un pretium doloris, es decir, el "precio del dolor".

Antônio Chaves (1985,) definió, en este sentido, el daño moral como "dolor resultante de la violación de un bien protegido legalmente, sin repercusiones patrimoniales. Ya sea que el dolor físico (sensación de dolor, como lo llama Carpenter) nazca de una lesión material; ya sea dolor moral (sentimiento de dolor) de causa material" (p. 607, traducción propia).

Pero desde esta perspectiva surgen dos problemas que se refieren a la operabilidad de la protección de la personalidad. El primero se refiere a una teratología. Imagine la situación en la que alguien ingresado en un hospital en estado de coma sufre injuria o difamación practicada por alguien que asigna acusaciones falsas y la práctica de actos ilícitos, sin que la víctima siquiera fuera condenada en ese sentido. ¿Tiene la víctima derecho a una indemnización por daños morales? Sí, lo hará, porque su honor (derecho de personalidad) ha sido dañado por las falsas noticias. ¿Pero, sintió la víctima alguna sensación de sufrimiento, dolor o humillación? No, no lo sintió. Por lo tanto, si prevalece la relación entre el daño moral y los sentimientos negativos (dolor, vergüenza, humillación o vergüenza), no sería posible hablar de daño moral.

1 En el original en portugués: "afirmar que o dano moral é 'dor, vexame, humilhação, ou constrangimento' é semelhante a dar-lhe o epíteto de 'mal evidente'. Através destes vocábulos, não se conceitua juridicamente, apenas se descrevem sensações e emoções desagradáveis, que podem ser justificáveis, compreensíveis, razoáveis, moralmente legítimas até, mas que, se não forem decorrentes de 'danos injustos', ou melhor, de danos a situações merecedoras da tutela por parte do ordenamento, não são reparáveis. [...]. Se a violação à situação jurídica subjetiva extrapatrimonial acarreta, ou não, um sentimento ruim, não é coisa que o Direito possa ou deva averiguar. O que o ordenamento jurídico pode (e deve) fazer é concretizar, ou densificar, a cláusula de proteção humana, não admitindo que violações à igualdade, à integridade psico-física, à liberdade e à solidariedade (social e familiar) permaneçam irressarcidas". 
Con respecto a esta caracterización, Marcelo Barrientos (2008) afirma que el pretium doloris representa una de las especies plausibles de daño moral, que en sí mismo es un concepto legal indeterminado mucho más amplio y complejo. Lo que sucede desde esta perspectiva es que a veces hay una miscelánea o confusión entre las consecuencias del daño moral y el daño mismo. Afirma, además, que la noción de pretium doloris causa errores y problemas prácticos al centrarse únicamente en las sensaciones. En este sentido, escribe, in verbis:

Homologar dolor, pesar, molestia, zozobra, inquietud, entre otros, sufridos por una persona como consecuencia de la conducta ajena, es un error manifiesto. ¿Cuáles son los límites? Sin precisarlos se les asigna una indemnización, en un monto que tampoco presenta mayores motivaciones y que la mayoría de las veces se basa en presunciones. (Barrientos, 2008, p. 94)

El segundo problema se refiere a la instrucción probatoria del dolor o sufrimiento. ¿Cómo probar una circunstancia psíquica, es decir, cómo demostrar que la víctima sufrió? Dicha comprobación consiste en verdadera probatio diabolica (a "prueba del diablo" o devil's proof), en la cual es imposible o muy difícil producir pruebas evidentes, lo que perjudica la compensación de la víctima (recuérdese el paradigma de la responsabilidad civil en Brasil es la reparación de la víctima).

\section{Sobre el elemento psíquico, Salomão Resedá (2017) afirma que}

si el objetivo es demostrar una reducción, en el caso de daño moral, esta disminución se trasladará a la tranquilidad espiritual, de ahí la necesidad de identificar sentimientos negativos para su configuración. La indemnización, entonces, sería por la ruptura de la paz interior. Aunque bastante seductora, esta línea de razonamiento debe analizarse con gran reserva. (p. 10, traducción propia)

En ese sentido, sobre la prueba del daño moral, destaca Humberto Theodoro Júnior (2016):

La lesión reparable como daño moral ocurre en el plano psíquico de la víctima, un terreno impenetrable por la investigación probatoria. Por lo tanto, la jurisprudencia se basa en la experiencia de la vida para analizar la gravedad de la agresión en función de la idoneidad del caso concreto de llegar a la psique de la víctima, con gravedad, de acuerdo con lo que sucede comúnmente. Por lo tanto, el demandante, que maneja el reclamo por daños, en especie, no está obligado a probar directamente el daño fuera del balance. Es solo para él probar la ocurrencia del hecho dañino, de cuyo contexto el juez extraerá la idoneidad, o no, para generar daños graves y relevantes, de acuerdo con la sensibilidad del hombre promedio y la experiencia de la vida. (p. 7, traducción propia) ${ }^{2}$

2 En el original en portugués: "A lesão reparável a título de dano moral ocorre no plano psíquico do ofendido, terreno impenetrável pela investigação probatória. Por isso, a jurisprudência se funda na experiência da vida para analisar a gravidade da agressão a partir da idoneidade do caso concreto de atingir o psiquismo da vítima, com gravidade, segundo o que comumente acontece. Assim, não se exige do demandante, manejador da pretensão indenizatória, na espécie, que prove diretamente o dano extrapatrimonial Cabe-lhe apenas comprovar a ocorrência do fato lesivo, de cujo contexto o juiz extrairá a idoneidade, 
A partir del Código Civil (2002), dada la imposibilidad de verificar los sentimientos negativos y de considerar el paradigma de reparación, se entendió que la compensación por daños morales no depende de la prueba de dolor o sufrimiento para configurar su exigibilidad.

De ahí que el daño moral se considere un prejuicio ipso jure: cualquier daño a un derecho de personalidad, independientemente de las sensaciones psíquicas que pueda causar a la víctima, se considera daño moral y, por lo tanto, debe ser compensado.

Si objetivamente hay una lesión en el deber de incolumidad de la persona, habrá daño moral in re ipsa, es decir, de pleno derecho.

Se entiende por daño moral in re ipsa aquella lesión que no depende de prueba de los sentimientos malos causados por el daño a la dignidad humana. La situación de hecho es suficiente (Medeiros Bahia y Gomes Medeiros, 2019, p. 41). Se trata de concebir el daño moral como presunción juris et de jure de prejuicio (Gonçalves, 2012).

Desde esta perspectiva, la víctima debe probar que el hecho es perjudicial para su personalidad al demostrar el derecho de personalidad violado. Se presume la pérdida no patrimonial derivada del hecho lesivo. Por lo tanto, el daño moral está in re ipsa, es decir, se deriva del hecho dañino mismo. Por lo tanto, no hay necesidad de pruebas de conmoción emocional y psicológica sufridas por la víctima.

El Tribunal Superior de Justicia entendió, desde al menos 1999, que para los casos de inscripción inadecuada en el registro negativo de protección de crédito, se presumirá el daño independientemente del sentimiento de la víctima. Vea, por ejemplo, el siguiente recurso especial sobre la inscripción de los deudores de Serasa:

La jurisprudencia de este Tribunal se consolida en el sentido de que en la concepción moderna de reparación por daño moral prevalece la orientación de que la responsabilidad del agente se efectúa en virtud del simple hecho de la violación, de tal manera que la prueba del daño concreto es innecesaria. La existencia de varios registros, al mismo tiempo, de otras deudas de los solicitantes, en el registro de deudores de Serasa, no disipa la presunción de existencia de daño moral, que surge in re ipsa, es decir, del registro mismo de un hecho inexistente. Hipótesis en la que las autoridades locales reconocieron categóricamente que la conducta del acusado en mantener incorrectamente los nombres de los solicitantes en el registro de los deudores era ilegal, incluso después de que la deuda fue cancelada. Recurso conocido en parte y, en esta parte, parcialmente proporcionado. (REsp. 196.024/ MG, 1999, traducción propia) $)^{3}$

ou não, para gerar dano grave e relevante, segundo a sensibilidade do homem médio e a experiência da vida".

3 En el original en portugués: "A jurisprudência desta Corte está consolidada no sentido de que na concepção moderna da reparação do dano moral prevalece a orientação de que a responsabilização do agente se opera por força do simples fato da violação, de modo a tornar-se desnecessária a prova do prejuízo em concreto. A existência de vários registros, na mesma época, de outros débitos dos recorrentes, no cadastro de devedores do Serasa, não afasta a presunção de existência do dano moral, que decorre in 
Después del Código Civil (2002) la comprensión de la instancia especial siguió siendo la misma:

La existencia de registros de otras deudas del solicitante en los organismos de restricción de crédito no disipa la presunción de la existencia de daño moral, que surge en re ipsa, es decir, del registro real de hecho inexistente. Anterior Hipótesis en la que el propio acusado reconoció el error al negar el nombre del solicitante. Recurso que se otorga. (REsp. 718.618/RS, 2005, traducción propia) ${ }^{4}$

Sin embargo, al menos desde 2008 el STJ se ha entendido de manera diferente: los daños morales no existirán en caso de registro incorrecto si hay otras inscripciones debidas, como es, verbi gratia, en la decisión del Agravo Regimental No Recurso Especial 1.081.845/RS:

La posición prevaleciente en el Tercer Panel de este tribunal era en el sentido de que la existencia de otras notas no eliminaría el deber de indemnizar, pero tendría un impacto en el arbitraje del monto de la indemnización. Sin embargo, el 14 de mayo de 2008, a juicio de REsp 1.002.985 / RS, el Ministro Relator Ary Pargendler, la Segunda Sección del STJ estableció un entendimiento de que la existencia de otros registros de mala reputación del nombre del deudor en los registros que protegen el crédito elimina la caracterización del daño moral. In casu, la sentencia recurrida destaca la existencia de otras reclamaciones de crédito, un hecho que con razón dio lugar a la desestimación de la reclamación de reparación moral. La sentencia recurrida también es irrecuperable, en el momento en que determina la cancelación de notas no precedidas por la comunicación al consumidor. (REsp. 1.081.845/RS, 2008, traducción propia) ${ }^{5}$

Este entendimiento prevaleció en otros recursos juzgados, tales como: REsp. 1.046.881/ RS (2008), REsp. 1.057.337/RS (2008), REsp. 1.002.985/RS (2008), REsp. 1.008.446/RS (2008).

En 2009, el Tribunal emitió la Súmula 385, en la que se declaró: "A partir de la anotación irregular en el registro de protección crediticia, no existe indemnización por

re ipsa, vale dizer, do próprio registro de fato inexistente. Hipótese em que as instâncias locais reconheceram categoricamente que foi ilícita a conduta da recorrida em manter, indevidamente, os nomes dos recorrentes, em cadastro de devedores, mesmo após a quitação da dívida. Recurso conhecido em parte e, nessa parte, parcialmente provido" (REsp. 196.024/MG, 1999).

4 En el original en portugués: "A existência de registros de outros débitos do recorrente em órgãos de restrição de crédito não afasta a presunção de existência do dano moral, que decorre in re ipsa, vale dizer, do próprio registro de fato inexistente. Precedente. Hipótese em que o próprio recorrido reconheceu o erro em negativar o nome do recorrente. Recurso a que se dá provimento" (REsp. 718.618/RS, 2005).

5 En el original en portugués: "[... o posicionamento prevalecente na Terceira Turma desta Corte era no sentido de que a existência de outras anotações não afastaria o dever de indenizar, mas repercutiria no arbitramento do valor da indenização. Entretanto, em 14/05/2008, no julgamento do REsp 1.002.985/ RS, Relator Ministro Ary Pargendler, a Segunda Seção do STJ firmou entendimento no sentido de que a existência de outros registros desabonatórios do nome do devedor em cadastros de proteção ao crédito afasta a caracterização do dano moral. In casu, o acórdão recorrido ressalta a existência de outras pendências creditícias, fato que ensejou, acertadamente, a improcedência do pleito de reparação moral. Irretorquível o acórdão recorrido, também, no ponto em que determina o cancelamento das anotações não precedidas de comunicação ao consumidor" (REsp. 1.081.845/RS,2008). 
daño moral, cuando exista registro legítimo, salvo derecho de cancelación" (Súmula 385, 2009, segunda sección, traducción propia).

Al profundizar la posición de la instancia especial con respecto a su comprensión del daño moral, se descubrió que en la década de 2010 el Tribunal alteró sustancialmente el sistema de compensación por daño moral, unas veces exigiendo evidencia de daño psicológico, otras veces presumiendo su existencia como resultado del hecho perjudicial.

\section{LOS ENTENDIMIENTOS RECIENTES DEL SUPERIOR TRIBUNAL DE JUSTICIA (STJ)}

Actualmente, la literatura jurídica comprende mayormente el daño moral como una violación de los derechos de la personalidad, es decir, los poderes conferidos a la persona por el derecho para garantizar sus aspectos fundamentales, a saber, psicosomático, moral e intelectual.

La evaluación y el análisis de las indemnizaciones relacionadas con daños morales tienen, a lo largo de la historia, diferentes criterios y requisitos para otorgarse. Desde un análisis del daño in re ipsa hasta una cuantificación del dolor o sufrimiento, los tribunales dudan sobre los criterios que se considerarán fundamentales para evaluar el daño moral y establecer el quantum compensatorio.

Al considerar la función de estandarizar la jurisprudencia nacional del Superior Tribunal de Justicia, se cuestionó cuál sería su entendimiento predominante para verificar si la instancia especial cumple con la posición mayoritaria de la literatura jurídica brasileña, a saber, que los daños morales son violaciones de pleno derecho de los derechos de la personalidad.

La investigación utilizó la herramienta de búsqueda de jurisprudencia en el sitio web del STJ y se desarrollaron los siguientes argumentos de búsqueda lógica:

- "dano moral"

- "dor" o "sofrimento" o "in re ipsa" o "direito da personalidade"

- "Primeira Turma" o "Segunda Turma" o "Terceira Turma" o "Quarta Turma"

El recorte temporal comprende el período entre el 1 de enero de 2014 y el 31 de diciembre de 2017.

Se identificaron un total de mil trecientas veinte decisiones que tenían en su contenido los requisitos exigidos por el argumento creado, es decir, recursos juzgados por las cuatro turmas del STJ que se ocupan del daño moral asociado con uno de los siguientes términos: "dor", "sofrimento", "in re ipsa" o "direito da personalidade". De este total, se analizaron ciento veinte casos juzgados (tabla 1). 
Tabla 1. Sistematización de la metodología de investigación

\begin{tabular}{ll}
\hline Sitio web de investigación & www.stj.jus.br (https://scon.stj.jus.br/SCON/) \\
\hline Período & 01/01/2014 a 31/12/2017 \\
\hline Criterios de búsqueda & 1) "dano moral" y "dor" o "sofrimento" o "in re ipsa" o \\
& "direito da personalidade" \\
& 2) "Primeira Turma" o "Segunda Turma" o "Terceira Turma" \\
& o "Quarta Turma" \\
\hline Método & Cualicuantitativa \\
\hline Documentos seleccionados & Solo acuerdos (recursos especiales y otros) \\
\hline Total de documentos encontrados & 1.320 \\
\hline Total de documentos seleccionados & 120 \\
\hline
\end{tabular}

Fuente: elaboración propia.

Del total de documentos encontrados, ciento veinte de ellos se utilizaron para estadísticas. Como resultado del amplio criterio de búsqueda, muchos juzgados que aparecieron fueron sobre diversos temas y asuntos no relacionados con la discusión central de la investigación. Por esta razón, los juzgados que no tenían relevancia para el objeto de la investigación, que consiste en la discusión en el STJ sobre cuál es la noción de daño moral, fueron descartados.

Un primer análisis de los documentos se refiere a la clasificación de las teorías del daño moral en el total investigado. La figura 1 muestra la división porcentual de las teorías en el total de años analizados:

\section{$2014-2017$}

- pretium doloris

in re ipsa

derechos de la personalidad

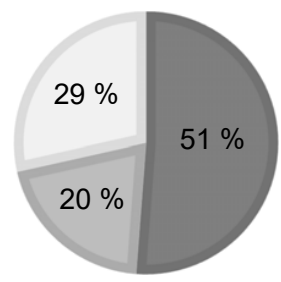

Figura 1. Porcentajes comparados con el total investigado

Fuente: elaboración propia.

Se realizó un segundo análisis que se muestra en la figura 2 para cada año analizado. La figura muestra los juzgados totales disponibles para cada año con el fin de verificar si la tendencia en cada año es consistente con la tendencia general: 
Análisis anual de teorías

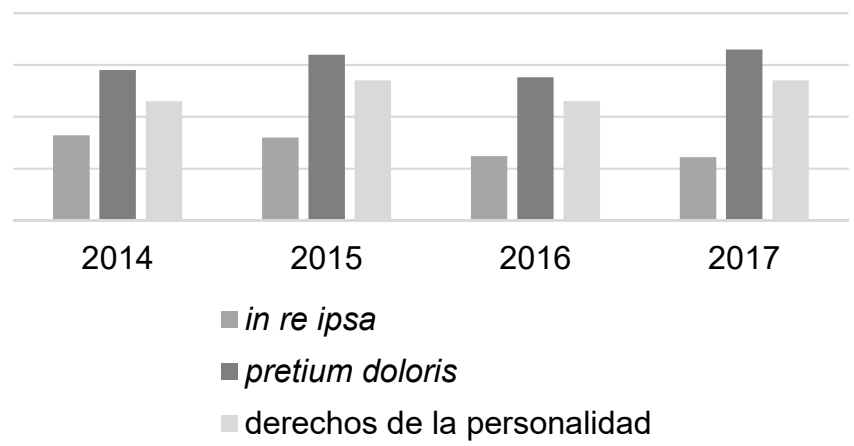

Figura 2. Tendencia para cada año

Fuente: elaboración propia.

En una monografía sobre el tema, Felipe Nobre de Morais (2013) realizó la prospección y el análisis de treinta y siete recursos de las cuatro turmas del Superior Tribunal de Justicia, desde enero de 2012 hasta agosto de 2013. En su análisis, identificó que el 67,56 \% de los casos analizados asocian daño moral a la identificación del elemento psíquico.

En la figura 3 se comparan los resultados de la investigación de 2013 con la actual para ver si la comprensión se mantendría constante o en tendencia.

\section{Comparación de investigaciones}

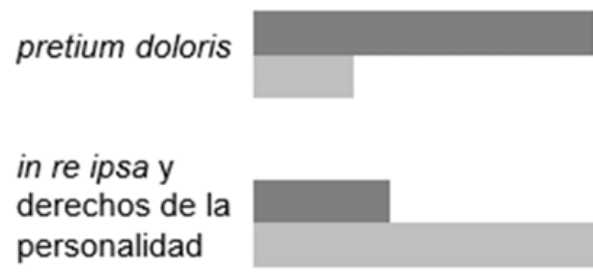

= invertigación anterior =investigación actual

Figura 3. Comparación entre la investigación actual y la investigación anterior

Fuente: elaboración propia.

Los datos obtenidos a través de la investigación en el Superior Tribunal de Justicia sobre el tema indican que hubo un cambio de comprensión en la instancia especial a partir de 2014. El cambio se trata de la necesidad de identificar elementos psíquicos para que se reconozca la existencia de daño moral. 
La investigación reveló, sin embargo, que la jurisprudencia del STJ presenta una noción más estrecha con respecto a la aplicación del presunto daño moral. En casos específicos, la Corte ha concluido que la compensación por daños no materiales es posible independientemente de la demostración de dolor y, como consecuencia, in re ipsa, intrínseca a la conducta en sí que injustamente lesa la dignidad humana.

Sin embargo, la caracterización del daño moral in re ipsa no puede ser extendida hasta el punto de descartar la necesidad de su demostración efectiva en cualquier situación. Esto se debe a que, al hacerlo, se estaría siguiendo el camino diametralmente opuesto al sentido de la despatrimonialización del derecho civil, lo que transforma el daño no patrimonial en un carácter meramente patrimonial y promueve la conocida "industria del daño moral" (Informativo de Jurisprudencia 627, 2018).

La figura 1 muestra que más de la mitad de los casos analizados adoptan la noción de daño moral in re ipsa. En un análisis no muy minucioso, este porcentaje parecía mostrar una contradicción entre los datos estadísticos obtenidos y el entendimiento del mismo STJ de que el daño moral generalmente no se presume y que el daño moral in re ipsa ocurre solo en casos específicos. Sin embargo, un análisis más detallado muestra que de los sesenta y dos recursos que tratan el daño moral como una lesión in re ipsa, treinta y seis de ellos son sobre problemas comunes, a saber: i) protesto indebido o inscripción indebida en el registro de impago; ii) mal uso de nombre o imagen; y iii) rechazo indebido del seguro de salud para autorizar la cobertura.

Está claro que el STJ no adopta como regla la presunción de daño moral, sino que establece situaciones específicas en las que esta presunción puede realizarse. Al sistematizar los fundamentos de las sesenta y dos decisiones encontramos que:

- El 100 \% corrobora la decisión con respecto al daño moral como in re ipsa (presunto).

- El 58 \% se refería a protestos indebidos o inscripción irregular en el registro de impago, uso indebido del nombre o imagen y rechazo indebido del seguro de salud para autorizar la cobertura. En ellos se aplicaba la noción tradicional de daño presunto.

- El 42 \% basó su propia idea, poco ortodoxa, en lo que el Tribunal concibe sobre el daño moral in re ipsa, por lo cual el daño se presume pero debe probarse. Esto quiere decir que la presunción de daño es juris tantum, no juris et de jure, como se sostiene tradicionalmente en la literatura jurídica.

Parece, entonces, que la idea que prevalece en la instancia especial con respecto a los sesenta y dos recursos juzgados es:

- En casos especiales de registro irregular en el registro de morosos, el uso indebido del nombre o la imagen, así como la negativa indebida de un seguro de salud para autorizar la cobertura, la presunción de daño moral es juris et de jure (presunción absoluta), es decir, es la expresión de una verdad. 
- En casos generales, la presunción de daño moral es juris tantum (presunción relativa).

Aún en la figura 1, se debe tener en cuenta que, a su vez, en el 29 \% de los recursos juzgados, el daño moral se caracteriza por corresponder a una violación de los derechos de la personalidad, mientras que en el $20 \%$ de los casos es posible hablar de daño moral como pretium doloris.

La figura 2 muestra que existe una uniformidad en estas proporciones durante los cuatro años investigados. Fue posible notar, como en el primer caso, el predominio del concepto de daño moral in re ipsa, seguido de la lesión de los derechos de la personalidad y, finalmente, la idea de que el daño moral debería expresar sufrimiento (pretium doloris).

La tabla 2 muestra la distribución de la noción de daño moral por turma del Superior Tribunal de Justicia y por año de juzgamiento:

Tabla 2. La noción de daño moral por turma y año en el Superior Tribunal de Justicia

\begin{tabular}{llc}
\hline Año & \multicolumn{1}{c}{ Noción de daño moral } & Turma \\
\hline 2014 & in re ipsa & Cuarta \\
\hline 2014 & in re ipsa & Tercera \\
\hline 2014 & in re ipsa & Segunda \\
\hline 2014 & derecho de la personalidad + pretium doloris & Tercera \\
\hline 2014 & derecho de la personalidad & Segunda \\
\hline 2014 & in re ipsa & Tercera \\
\hline 2014 & derecho de la personalidad & Cuarta \\
\hline 2014 & in re ipsa & Cuarta \\
\hline 2014 & pretium doloris & Segunda \\
\hline 2014 & pretium doloris & Tercera \\
\hline 2014 & pretium doloris & Segunda \\
\hline 2014 & derecho de la personalidad + in re ipsa & Cuarta \\
\hline 2014 & pretium doloris & Segunda \\
\hline 2014 & in re ipsa & Tercera \\
\hline 2014 & in re ipsa & Cuarta \\
\hline 2014 & in re ipsa & Tercera \\
\hline 2014 & in re ipsa & Cuarta \\
\hline 2014 & in re ipsa & Cuarta \\
\hline 2014 & derecho de la personalidad & Tercera \\
\hline 2014 & in re ipsa & Cuarta \\
\hline 2014 & in re ipsa & Primera \\
\hline
\end{tabular}


Gilberto Fachetti Silvestre y Bruna Figueira Marchiori

\begin{tabular}{|c|c|c|}
\hline Año & Noción de daño moral & Turma \\
\hline 2014 & pretium doloris & Tercera \\
\hline 2014 & derecho de la personalidad & Cuarta \\
\hline 2014 & in re ipsa & Tercera \\
\hline 2014 & pretium doloris & Cuarta \\
\hline 2014 & in re ipsa & Primera \\
\hline 2014 & in re ipsa & Tercera \\
\hline 2014 & in re ipsa & Cuarta \\
\hline 2014 & in re ipsa & Cuarta \\
\hline 2014 & in re ipsa & Primera \\
\hline 2015 & in re ipsa & Tercera \\
\hline 2015 & in re ipsa & Tercera \\
\hline 2015 & derecho de la personalidad & Segunda \\
\hline 2015 & in re ipsa & Segunda \\
\hline 2015 & derecho de la personalidad + in re ipsa & Tercera \\
\hline 2015 & in re ipsa & Tercera \\
\hline 2015 & derecho de la personalidad & Segunda \\
\hline 2015 & pretium doloris & Tercera \\
\hline 2015 & in re ipsa & Tercera \\
\hline 2015 & pretium doloris & Cuarta \\
\hline 2015 & derecho de la personalidad & Segunda \\
\hline 2015 & in re ipsa & Cuarta \\
\hline 2015 & in re ipsa & Cuarta \\
\hline 2015 & derecho de la personalidad & Cuarta \\
\hline 2015 & derecho de la personalidad & Tercera \\
\hline 2015 & in re ipsa & Tercera \\
\hline 2015 & in re ipsa & Tercera \\
\hline 2015 & in re ipsa & Cuarta \\
\hline 2015 & derecho de la personalidad & Cuarta \\
\hline 2015 & pretium doloris & Cuarta \\
\hline 2015 & pretium doloris & Cuarta \\
\hline 2015 & in re ipsa & Tercera \\
\hline 2015 & in re ipsa & Cuarta \\
\hline 2015 & in re ipsa & Cuarta \\
\hline 2015 & pretium doloris & Tercera \\
\hline
\end{tabular}




\begin{tabular}{|c|c|c|}
\hline Año & Noción de daño moral & Turma \\
\hline 2015 & derecho de la personalidad & Cuarta \\
\hline 2015 & derecho de la personalidad & Tercera \\
\hline 2015 & in re ipsa & Tercera \\
\hline 2015 & derecho de la personalidad & Cuarta \\
\hline 2015 & in re ipsa & Cuarta \\
\hline 2016 & derecho de la personalidad & Cuarta \\
\hline 2016 & derecho de la personalidad & Tercera \\
\hline 2016 & derecho de la personalidad & Tercera \\
\hline 2016 & in re ipsa & Cuarta \\
\hline 2016 & in re ipsa & Cuarta \\
\hline 2016 & pretium doloris & Tercera \\
\hline 2016 & derecho de la personalidad & Tercera \\
\hline 2016 & pretium doloris & Cuarta \\
\hline 2016 & pretium doloris & Cuarta \\
\hline 2016 & pretium doloris & Segunda \\
\hline 2016 & in re ipsa & Cuarta \\
\hline 2016 & in re ipsa & Tercera \\
\hline 2016 & in re ipsa & Tercera \\
\hline 2016 & derecho de la personalidad & Tercera \\
\hline 2016 & pretium doloris & Segunda \\
\hline 2016 & pretium doloris & Tercera \\
\hline 2016 & in re ipsa & Tercera \\
\hline 2016 & in re ipsa & Cuarta \\
\hline 2016 & derecho de la personalidad & Segunda \\
\hline 2016 & in re ipsa & Tercera \\
\hline 2016 & derecho de la personalidad & Cuarta \\
\hline 2016 & in re ipsa & Tercera \\
\hline 2016 & in re ipsa & Cuarta \\
\hline 2016 & in re ipsa & Cuarta \\
\hline 2016 & in re ipsa & Tercera \\
\hline 2016 & in re ipsa & Cuarta \\
\hline 2016 & in re ipsa & Cuarta \\
\hline 2016 & in re ipsa & Tercera \\
\hline 2016 & in re ipsa & Primera \\
\hline
\end{tabular}


Gilberto Fachetti Silvestre y Bruna Figueira Marchiori

\begin{tabular}{|c|c|c|}
\hline Año & Noción de daño moral & Turma \\
\hline 2016 & derecho de la personalidad & Tercera \\
\hline 2017 & in re ipsa & Segunda \\
\hline 2017 & in re ipsa & Cuarta \\
\hline 2017 & derecho de la personalidad & Tercera \\
\hline 2017 & derecho de la personalidad & Segunda \\
\hline 2017 & in re ipsa & Cuarta \\
\hline 2017 & in re ipsa & Segunda \\
\hline 2017 & derecho de la personalidad & Cuarta \\
\hline 2017 & pretium doloris & Cuarta \\
\hline 2017 & pretium doloris & Cuarta \\
\hline 2017 & pretium doloris & Segunda \\
\hline 2017 & derecho de la personalidad & Cuarta \\
\hline 2017 & in re ipsa & Tercera \\
\hline 2017 & derecho de la personalidad & Cuarta \\
\hline 2017 & in re ipsa & Cuarta \\
\hline 2017 & in re ipsa & Tercera \\
\hline 2017 & pretium doloris & Tercera \\
\hline 2017 & derecho de la personalidad & Tercera \\
\hline 2017 & in re ipsa & Tercera \\
\hline 2017 & derecho de la personalidad & Tercera \\
\hline 2017 & in re ipsa & Tercera \\
\hline 2017 & in re ipsa & Tercera \\
\hline 2017 & pretium doloris & Segunda \\
\hline 2017 & derecho de la personalidad & Cuarta \\
\hline 2017 & derecho de la personalidad & Primera \\
\hline 2017 & derecho de la personalidad & Tercera \\
\hline 2017 & in re ipsa & Cuarta \\
\hline 2017 & pretium doloris & Cuarta \\
\hline 2017 & in re ipsa & Cuarta \\
\hline 2017 & pretium doloris & Cuarta \\
\hline 2017 & derecho de la personalidad & Cuarta \\
\hline
\end{tabular}

Fuente: elaboración propia.

La figura 3 permite identificar la ocurrencia o no de un cambio en la comprensión del STJ en tiempos más recientes. Para llegar a esta conclusión, se realizó un análisis 
comparativo de la investigación de 2018 y la anterior, realizada por Felipe Nobre de Morais (2013), en 2013 (período entre enero de 2012 y agosto de 2013).

En su investigación, Felipe Nobre de Morais identificó que en aproximadamente el $68 \%$ de los juzgados existe una asociación entre el daño moral y el sufrimiento (pretium doloris). A su vez, realiza el análisis de los otros dos temas juntos, a saber, el daño moral in re ipsa y el daño moral como una violación de los derechos de la personalidad. En este sentido, justifica la elección de este criterio afirmando que "un daño a los derechos de la personalidad no requiere prueba o evidencia de elementos psíquicos, ya que es un daño moral in re ipsa" (2013, p. 51, traducción propia).

Esta investigación de 2018 llevó a cabo el tratamiento de datos de manera similar a la realizada en 2013, como se muestra en la figura 3, para poder realizar un análisis comparativo.

Se percibe un cambio en el entendimiento del Tribunal Superior de Justicia ya que la instancia especial no requirió, en la mayoría de los casos analizados entre 2014 y 2017, alteraciones del alma para la configuración del daño moral. En la investigación realizada entre 2012 y 2013, aproximadamente el $30 \%$ de los ministros utilizaron las nociones de daño moral como una violación de los derechos de la personalidad y el daño moral en conjunto. Por otro lado, en la investigación de 2018, aproximadamente el $80 \%$ de los ministros hizo referencia directa o indirectamente a esos mismos conceptos. Este giro de la comprensión es extremadamente relevante.

Salomão Resedá (2017) resume las observaciones que se han hecho en la literatura jurídica durante mucho tiempo: entender el daño moral simplemente como un delito contra los derechos de la personalidad, permite el establecimiento de contornos que terminan limitando las hipótesis de configuración que contienen el miedo generalizado a la "industrialización del daño moral", es decir, la trivialización del instituto.

En este sentido, comenta José Joaquim Calmon de Passos (2002):

Esta percepción mía siempre me ha llevado a no entender cuál es la famosa reparación del dolor experimentado por alguien, asociado con el acto del sujeto a quien se le atribuye que lo causó y que, de no haber sido así, nunca habría sido experimentado. Nada más susceptible de subjetivar que el dolor, ni nada más fácil de desconcertar. Así como hubo dolientes que lloraron el dolor de aquellos que no pudieron llorar porque no lo experimentaron, también nos volvimos extremadamente expertos en hacernos dolientes, llorar, por el espectáculo frente a otros, el dolor que en verdad no lo hemos probado. La posibilidad, incluso, de obtener beneficios financieros de nuestro dolor oculto, nos convirtió en actores excepcionales y extremadamente hábiles, ya sea como víctimas, como abogados o magistrados. (p. 08, traducción propia) ${ }^{6}$

6 En el original en portugués: "Essa minha percepção sempre me levou a não compreender o que seja a famosa reparação pela dor experimentada por alguém, associada ao ato do sujeito a quem se atribui tê-la provocado e que, não fora isso, jamais teria sido experimentada. Nada mais suscetível de subjetivizar-se 
Aunque la presencia de dolor o sufrimiento es un posible resultado del daño moral y es un elemento que lo resalta, no es una manifestación sine quibus non para representar el daño moral en sí, ni se presenta como indispensable (sine quce non) para su configuración.

Por lo tanto, Maria Helena Diniz (2003) entiende que el individuo puede reclamar una compensación, no como un "valor" de su dolor o sufrimiento, sino como un alivio de su dolor:

el derecho no repara el dolor, el sufrimiento o la angustia, sino solo los daños que resultan de la privación de un activo sobre el cual la persona lesionada tendría un interés legalmente reconocido. La persona lesionada puede reclamar una indemnización monetaria debido al daño moral, sin pedir un precio por su dolor, sino un alivio que mitiga en parte las consecuencias del daño sufrido, mejorando su futuro, superando el déficit causado por el daño. (p. 85, traducción propia) ${ }^{7}$

Lo que se hizo en esta investigación fue una inferencia estadística cuyo objetivo era obtener información sobre las características de daño moral de un espacio de muestra. A pesar del criterio de aleatoriedad en la selección del material, es posible que exista una ligera discrepancia al hacer la inferencia del asunto. El marco metodológico y técnico-científico es el propuesto por Wilton Bussab y Pedro Morettin (2010).

Es difícil obtener información precisa sobre la distribución del material en las tres categorías seleccionadas en el trabajo. Sin embargo, el número de recursos juzgados tomados como muestra, ciento veinte, fue significativo para esta estadística, lo que garantiza una inferencia confiable.

\section{CONCLUSIONES}

Es posible suponer las causas que llevaron al Superior Tribunal de Justicia (STJ) a exigir pruebas del elemento psíquico en el período de principios de la década de 2010. Es de sentido común hablar, hoy en día, de "trivialización del daño moral" e "industria del daño moral". El requisito del dolor para configurar el daño moral demuestra que debe ser visto como una lesión excepcional y grave a los derechos de la personalidad, lejos de cualquier exceso de susceptibilidades o molestias cotidianas. Por lo tanto,

que a dor, nem nada mais fácil de ser objeto de mistificação. Assim como já existiram carpideiras que choravam a dor dos que eram incapazes de chora-la, porque não a experimentavam, também nos tornamos extremamente hábeis em nos fazermos carpideiras de nós mesmos, chorando, para o espetáculo diante dos outros, a dor que em verdade não experimentamos. A possibilidade, inclusive, de retiramos proveitos financeiros dessa nossa dor oculta, fez-nos atores excepcionais e meliantes extremamente hábeis, quer como vítimas, quer como advogados ou magistrados".

7 En el original en portugués: "o direito não repara a dor, a mágoa, o sofrimento ou a angústia, mas apenas aqueles danos que resultarem da privação de um bem sobre o qual o lesado teria interesse reconhecido juridicamente. O lesado pode pleitear uma indenização pecuniária em razão de dano moral, sem pedir um preço para sua dor, mas um lenitivo que atenue, em parte, as conseqüências do prejuízo sofrido, melhorando seu futuro, superando o déficit acarretado pelo dano". 
no todo es daño moral y no todas las situaciones de disgusto deben convertirse en una demanda y llevarse a los tribunales.

Tiene sentido, entonces, que el STJ sea más riguroso en demostrar daño moral. De esta manera surge una nueva cultura en torno a la comprensión del asunto y, en consecuencia, una disminución de las demandas judiciales.

Ocurre que, a partir de 2014, el Tribunal Superior vuelve a la caracterización objetiva del daño moral y supone que es una lesión del derecho de la personalidad que causa, in re ipsa, daño a la dignidad y la personalidad del sujeto.

No hubo cambios significativos en la composición de ministros de las turmas que juzgan el asunto en casos civiles.

Por esta razón, no existe una explicación objetiva (pública) para tal cambio en el estándar, aparte de una impresión personal o suposición dentro del alcance de esta investigación: las turmas de la Corte tenían la percepción de que la posición anterior constituye una verdadera prueba diabólica e injusta contra la víctima. En este sentido, se contradice el paradigma de responsabilidad civil y el Derecho de Daños que actualmente prevalece en la Corte en materia civil: la inexorable exigencia de indemnizar a alguien que sufrió daños (paradigma de la víctima).

Por lo tanto, sea como sea, se demuestra que, tanto en términos teóricos como en términos de operatividad, la comprensión del tema "daño moral" aún no es consensuada en el entorno literario, forense y en la instancia superior a pesar de ser una discusión de muchas décadas (sin mencionar casi secular).

\section{REFERENCIAS}

Barrientos, M. (2008). Del daño moral al daño extrapatrimonial: la superación del pretium doloris. Revista Chilena de Derecho, 35(1), 85-106.

Brasil. (1988). Constituição da República Federativa do Brasil. http://www.planalto.gov.br/ccivil_03/ constituicao/constituicaocompilado.htm

Brasil. (2002, 10 de enero). Ley 10.406. Código Civil. http://www.planalto.gov.br/ccivil_03/leis/2002/ L10406compilada.htm

Brasil. (2015, 16 de marzo). Ley 13.105. Código de Processo Civil. http://www.planalto.gov.br/ccivil_03/_ ato2015-2018/2015/lei/113105.htm

Bodin de Moraes, M. C. (2003). Danos à pessoa humana: uma leitura civil-constitucional dos danos morais. Renovar.

Bussab, W. O. y Morettin, P. A. (2010). Estatística básica (6. a ed.). Saraiva.

Calmon de Passos, J. J. (2002). O imoral nas indenizações por dano moral. Grandes temas da atualidade: dano moral: aspectos constitucionais, civis, penais e trabalhistas. Forense.

Cavalieri Filho, S. (2003). Programa de responsabilidade civil (4. ${ }^{\text {a }}$ ed.). Malheiros. 
Chaves, A. (1985). Tratado de Direito Civil (vol. III). Revista dos Tribunais.

Chironi, G. (1925). La colpa nel diritto civile odierno: colpa extra-contrattuale. F. Bocca.

Conselho Nacional de Justiça, CNJ (2017). Justiça em números. Conselho Nacional de Justiça. https://www. cnj.jus.br/wp-content/uploads/2019/08/b60a659e5d5cb79337945cldd137496c.pdf

Da Silva Pereira, C. M. (2002). Instituições de Direito Civil (19. ${ }^{\mathrm{a}}$ ed.). Forense.

De Salvo Venosa, S. (2004). Direito Civil: responsabilidade civil (4. ${ }^{\text {a }}$ ed., vol. IV). Atlas.

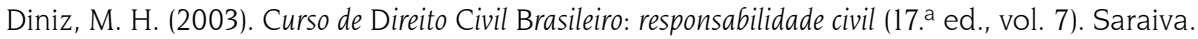

Gonçalves, C. R. (2012). Direito Civil Brasileiro: responsabilidade civil (7. a ed.). Saraiva.

Mazeaud, H. y Mazeaud, L. (1934). Traité Théorique et Pratique de la Responsabileté Civile (T. 1). Librairie Du Recueil Sirey.

Medeiros Bahia, C., y Gomes Medeiros, H. (2019). Daño moral colectivo en las relaciones de consumo: caracterización, comparación entre el sistema brasileño y colombiano y la visión del Tribunal Superior de Justicia en Brasil. Opinión Jurídica, 18(36), 37-55. https://doi.org/10.22395/ojum.v18n36a2

Nobre de Morais, F. (2013). Danos morais no STJ: preço da dor? Universidade Federal do Espírito Santo.

Noronha, F. (2013). Direito das obrigações (4. ${ }^{\text {a }}$ ed.). Saraiva.

Resedá, S. (2017). Dor e dano: dois "d" diferentes. Um ensaio sobre os sentimentos negativos e o dano moral. Direito Unifacs, 1(1), 01-10.

Silvestre, G. F., Hibner, D. A. y Ramalho, C. V. N (2018). La accesibilidad como un nuevo derecho de la personalidad en Brasil: el Estatuto de la Persona con Discapacidad (ley 13.146/2015) y el daño moral que surge de la inaccesibilidad. Derecho PUCP — Revista de la Faculdad de Derecho da Pontificia Universidad Catolica del Peru, 80, 9-31.

Silvestre, G. F., Hibner, D. A. y Ramalho, C. V. N. (2018). Acessibilidade e direitos da personalidade: questões materiais e processuais. Novas Edições Acadêmicas.

Silvestre, G. F., Silva, A. C. y Schneider, F. B. A. (2017). Critérios de fixação do quantum compensatório do dano moral. Revista Jurídica Luso-Brasileira, 2, 37-69.

Superior Tribunal de Justiça (1999, 2 de febrero). Recurso Especial 196.024/MG (Relator Ministro César Asfor Rocha). http://www.stj.gov.br/SCON/jurisprudencia/doc.jsp?processo $=2633 \mathcal{E} E b=$ ACOREp $=$ true $E \mathrm{t}=\mathcal{E}=10 \mathcal{E} \mathrm{i}=1$

Superior Tribunal de Justiça (2005, 24 de mayo). Recurso Especial 718.618/RS (Relator Ministro Antônio de Pádua Ribeiro). http://www.stj.gov.br/SCON/jurisprudencia/doc.jsp?processo $=6631 \mathrm{~Eb}=\mathrm{ACO}$ $R E p=$ trueEt $=\varepsilon l=10 \xi \mathrm{i}=2$

Superior Tribunal de Justiça (2008, 12 de abril). Recurso Especial 1.081.845/RS (Relator Ministro Massami Uyeda). http://www.stj.gov.br/SCON/jurisprudencia/doc.jsp?processo $=6196 \varepsilon b=A C O R E p=$ trueE $\mathrm{t}=\varepsilon \mathrm{l}=10 \mathcal{E} \mathrm{i}=2$

Superior Tribunal de Justiça. (2008, 09 de diciembre). Recurso Especial 1.046.881/RS (Relator Ministro João Otávio de Noronha). https://ww2.stj.jus.br/processo/revista/documento/mediado/?compon ente $=$ MONEsequencial $=108446188 \&$ num_registro $=202000841989 \varepsilon$ data $=200814$ 
Superior Tribunal de Justiça. (2008, 04 de septiembre). Recurso Especial 1.057.337/RS (Relator Ministro Sidnei Beneti). https://stj.jusbrasil.com.br/jurisprudencia/837530/agravo-regimental-no-recursoespecial-agrg-no-resp-1057337-rs-2008-0102640-4/inteiro-teor-12771822

Superior Tribunal de Justiça. (2008, 14 de mayo). Recurso Especial 1.002.985/RS (Relator Ministro Ari Pargendler). https://ww2.stj.jus.br/processo/dj/documento/mediado/?tipo_documento=docume ntoEcomponente $=$ sequencial $=108546980 E$ Enum_registro $=200857694 \&$ data $=20209717$

Superior Tribunal de Justiça. (2008, 08 de abril). Recurso Especial 1.008.446/RS (Relator Ministro Aldir Passarinho Júnior). https://ww2.stj.jus.br/processo/decisoes/?num_registro=2008085247Etpubl icacao $=484456495867$

Superior Tribunal de Justiça (2009). Súmula 385. https://ww2.stj.jus.br/docs_internet/revista/eletronica/ stj-revista-sumulas-2013_35_capSumula385.pdf

Superior Tribunal de Justiça (2018). Informativo de Jurisprudência 627. https://ww2.stj.jus.br/ publicacaoinstitucional/index.php/informjurisdata/issue/view/583

Theodoro Júnior, H. (2016). Dano moral (8. ${ }^{a}$ ed.). Forense. 